\title{
Acceptance of COVID-19 Vaccination Among Health System Personnel
}

\author{
Daniel J. Parente, MD, PhD, Akinlolu Ojo, MD, PhD, MBA, Tami Gurley, PhD, \\ Joseph W. LeMaster, MD, MPH, Mark Meyer, MD, David M. Wild, MD, MBA, and \\ Reem A. Mustafa, MBBS, PhD, MPH
}

Introduction: One-third of the general public will not accept Coronavirus disease 2019 (COVID-19) vaccination but factors influencing vaccine acceptance among health care personnel (HCP) are not known. We investigated barriers and facilitators to vaccine acceptance within 3 months of regulatory approval (primary outcome) among adult employees and students at a tertiary-care, academic medical center.

Methods: We used a cross-sectional survey design with multivariable logistic regression. Covariates included age, gender, educational attainment, self-reported health status, concern about CoVID-19, direct patient interaction, and prior influenza immunization.

Results: of 18,250 eligible persons, 3,347 participated. Two in 5 (40.5\%) HCP intend to delay ( $\mathrm{n}=$ 1020; 30.6\%) or forgo $(n=331 ; 9.9 \%)$ vaccination. Male sex (adjusted OR [aOR], $2.43 ; 95 \%$ confidence interval $[\mathrm{CI}], 2.00-2.95 ; P<.001)$, prior influenza vaccination $(\mathrm{aOR}, 2.35 ; 95 \% \mathrm{CI}, 1.75-3.18 ; \boldsymbol{P}<.001)$, increased concern about COVID-19 (aOR, 2.40; 95\% CI, 2.07-2.79; $P<.001)$, and postgraduate education (aOR, 1.41; 95\% CI, 1.21-1.65; $P<.001$ ) - but not age, direct patient interaction, or self-reported overall health - were associated with vaccine acceptance in multivariable analysis. Barriers to vaccination included concerns about long-term side effects $(n=1197,57.1 \%)$, safety $(n=1152,55.0 \%)$, efficacy $(n=777,37.1 \%)$, risk-to-benefit ratio $(n=650,31.0 \%)$, and cost $(n=255,12.2 \%)$.

Subgroup analysis of Black respondents indicates greater hesitancy to accept vaccination (only $24.8 \%$ within 3 months; aOR $0.13 ; 95 \%$ CI, 0.08-0.21; $P<.001)$.

Conclusions: Many HCP intend to delay or refuse COVID-19 vaccination. Policymakers should impartially address concerns about safety, efficacy, side effects, risk-to-benefit ratio, and cost. Further research with minority subgroups is urgently needed. (J Am Board Fam Med 2021;34:498-508.)

Keywords: Academic Medical Centers, Acute Disease, Chronic Disease, CoVID-19, Cross-Sectional Studies, Health Personnel, Linear Models, Logistic Models, Outpatients, Pandemics, Primary Health Care, Quality of Life, Self Report, Surveys and Questionnaires, Vaccination

\section{Introduction}

Severe acute respiratory syndrome coronavirus 2 (SARS-CoV-2), the etiologic agent of Coronavirus

This article was externally peer reviewed.

From the Department of Family Medicine and Community Health (DJP, MM, JW), School of Medicine (AO, MM), Department of Population Health (TG), Department of Anesthesiology (DMW), Department of Internal Medicine, Division of Nephrology and Hypertension (RAM), University of Kansas Medical Center, Kansas City.

Funding: Statement: This work was not externally funded but utilized the REDCap survey platform at the University of Kansas Medical Center, which was supported by a Clinical and Translational Science Award (CTSA) grant from the National Center for Advancing Translational Sciences (NCATS) awarded to the University of Kansas for Frontiers: University of Kansas Clinical and Translational Science Institute (\#UL1TR002366). This work is solely the responsibility of the authors and does not necessarily represent the official views of the National Institutes of Health or NCATS. This agency had disease 2019 (COVID-19), is a respiratory virus that has killed millions worldwide. ${ }^{1}$ Many COVID19 vaccines are under development and rely on widely divergent scientific approaches. ${ }^{2,3}$ Through "Operation Warp Speed," the United States government has targeted delivering 300 million doses of a safe and effective vaccine by January 2021.,4 The Food and Drug Administration (FDA) has now issued emergency use authorization (EUA) for

no role in the design and conduct of the study; collection, management, analysis, and interpretation of the data; preparation, review, or approval of the manuscript; or decision to submit the manuscript for publication.

Conflict of interest: None.

Corresponding author: Daniel J. Parente, MD, PhD, 3901 Rainbow Blvd, MS 4010, Kansas City, KS 66160, Phone: $913-$ 945-8054, Fax: 913-588-2095 (E-mail: dparente@kumc.edu). 
2 mRNA-based vaccines developed by Pfizer/ BioNTech (BNT162b2) and Moderna (MRNA1273). ${ }^{5-8}$ These vaccines are the fastest ever developed. $^{2}$ Health care personnel (HCP) are at increased risk of COVID-19 infection. ${ }^{9}$ Health systems - in analogy to seasonal influenza campaigns have begun efforts to promote workforce COVID19 vaccine uptake. Recent analyses show that vaccine acceptance may be limited among the general public as between $10 \%$ to $35 \%$ of the individuals indicate that they will not accept a COVID-19 vaccine. ${ }^{10-12}$ COVID-19 vaccine acceptance among the general population has been associated with age, sex, race, marital status, educational attainment, political ideology, trust in media/health agencies/scientists, fear of COVID-19, perceived severity of the COVID-19 pandemic, level of vaccine efficacy, duration of vaccine protection, frequency of reported adverse effects, attitudes toward vaccination in general and prior influenza vaccination. ${ }^{11-17}$ An analysis using a behavioral economics approach also showed that rapid vaccine development suppressed vaccine uptake at the same level of effectiveness. ${ }^{13}$ FDA emergency use authorization, as compared with full FDA approval, was also associated with decreased vaccine acceptance. ${ }^{16}$

Moreover, health care worker acceptance of influenza vaccination during an influenza pandemic - the most analogous vaccine-preventable disease for which there is significant data - indicates that vaccination uptake is greater in males, physicians, nurses, full-time employees, and persons who perceive greater disease risk. ${ }^{18}$ Mandated vaccination by health care institutions was also markedly associated with influenza vaccination uptake (from $45 \%$ to $90 \%){ }^{19}$

Data were lacking, however, on attitudes toward COVID-19 vaccination among HCPs. Some new data has become available while this article was under review. A survey of the French public found that HCP were more likely to accept vaccination (multivariable odds ratio [OR], 1.53). ${ }^{20}$ A French survey specifically targeting 2047 HCPs showed $76.9 \%$ would accept vaccination and that age, gender, fear of COVID-19, perceived individual risk and prior influenza vaccination promoted vaccine uptake. ${ }^{21}$ Acceptance of COVID-19 vaccination, however, among HCP varies significantly by geographic location. ${ }^{22}$ For example, in a survey of 613 HCPs in the Democratic Republic of Congo, only $27.7 \%$ would accept COVID-19 vaccination, and vaccination was promoted by male sex and physician (vs non-physician) job role. ${ }^{23}$ An online survey of 1205 nurses in Hong Kong indicated that 63\% intended to accept COVID-19 vaccination; interestingly, this exceeded the rate of influenza vaccine uptake (49\%). ${ }^{24}$ In a separate study by the same research group, vaccine acceptance among Hong Kong nurses was positively associated with private sector employment, chronic medical problems, encounters with known or suspected COVID-19 patients, and prior influenza vaccination. ${ }^{25}$ Here, we evaluated HCP willingness to become vaccinated against COVID-19 and identified barriers/ facilitators to vaccine uptake among all personnel at a large academic medical center in the Midwest United States.

\section{Methods}

\section{Study Population and Survey Implementation}

Anonymous, electronic surveys in English were emailed to approximately 18,250 employees, faculty, and students at the University of Kansas Medical Center (comprising the ambulatory clinics and >750-bed hospital of the University of Kansas Health System; and the Schools of Medicine, Nursing and Health Professions) between August 14, 2020, and August 28, 2020. Individuals under the age of 18 years were excluded. Participants in the health system were sent e-mails through the health system's Corporate Communication division using internal e-mail lists. Participants in the university were e-mailed through broadcast e-mails to the Schools of Medicine, Nursing, and Health Professions. Participants completed the survey electronically through the REDCap survey platform. ${ }^{26,27}$ Two invitations were sent: an initial invitation and a reminder 1 week later. All medical center personnel were included in our definition of "health care personnel" and invited to participate. Potential respondents therefore comprised a wide range of clinical and non-clinical roles: for example, physicians, advanced practice providers, nurses, respiratory therapists, front-desk staff, dietary staff, administrative staff, university research staff, and other personnel.

Our prespecified hypotheses were that (1) most health care personnel would accept vaccination, (2) safety concerns would be the predominant barrier to vaccination uptake among those delaying vaccination, (3) job responsibilities involving direct 
patient interaction would facilitate vaccine acceptance, and (4) that educational attainment would be associated with vaccine acceptance. Survey content was developed by the principal investigator and research team, based on a review of the literature of similar published studies, ${ }^{11-17}$ to interrogate these hypotheses and control for relevant covariables. A draft of the surveys was discussed with stakeholders within the health system, university, and local county health department for comment. After incorporating feedback, these same stakeholders piloted the survey before the wide distribution of the survey.

\section{Measures}

Surveys queried participant intention to become vaccinated against COVID-19 following regulatory approval by the FDA (within the first month of approval, 1 to 3 months after approval, 4 to 6 months after approval, 7 to 12 months after approval, more than 12 months after approval, or never). Early acceptance of COVID-19 vaccination (primary outcome) was defined as the intention to receive vaccination within 3 months of regulatory approval. Participants were considered to delay - but not forgo - vaccination if they planned to obtain the vaccination at least 3 months after approval. Barriers to vaccination were assessed among participants planning to delay ( $>3$ months) or forgo vaccination. Self-reported health status, level of concern about COVID-19, prior diagnosis of COVID-19, prior positive antibody testing, participation in ongoing COVID-19 vaccine trials, job responsibility involving direct patient interaction and in caring for patients with known COVID-19, clinical role, influenza immunization in the 2019 to 2020 season and demographic parameters (age, sex, race, ethnicity, and educational attainment) were also collected. To assess for response bias, aggregate demographics of the entire eligible population were estimated from employee and student records obtained from the Health System Human Resources department and University Office of Enterprise Analytics (Appendix Table 1).

Age data were collected on the survey in categories (ie, 18 to 24 years, 24 to 29 years, 30 to 34 years, etc.). In the regression model, age was centered to the median of the respective category (eg, 30 to 34 years was modeled as 32 years). History of influenza vaccination and job responsibilities involving direct patient interaction were dichotomous and used directly without any transformation. Sex was already nearly dichotomous (man/woman); 7 respondents $(0.2 \%)$ reported "other" sex, which was treated as missing data in the regression because of its extreme infrequency. Concern about COVID-19 infection was collected on a 5-point Likert scale (extremely, moderately, somewhat, slightly, not at all) and was dichotomized between extreme/moderately and somewhat/slight/not at all. Self-reported health was also collected on a 5-point Likert scale (excellent, very good, good, fair, poor), following Ware and colleagues, ${ }^{28}$ and was dichotomized between very good or better and good or worse. Finally, educational attainment was collected on a 6point Likert scale (some high school, high school graduate, some college, college graduate, Master's degree and Doctoral/Professional degree) and was dichotomized between college graduate or less and Master's degree or greater. Dichotomization was undertaken to minimize the number of free model parameters and because nonlinear effects were not expected within a level of concern about COVID-19, self-reported health status, and educational attainment. For example, we hypothesized, dichotomously, that persons with greater concern would be more likely to accept vaccination than a person with less concern. We did not expect, a priori, a nonlinear effect such as persons who were "extremely" and "slightly" concerned might both have high acceptance, but persons "moderately" concerned to have low acceptance).

\section{Statistical Analysis}

Bivariable and multivariable logistic regression modeling was conducted using $\mathrm{R}$ version 3.6.1 (The R Foundation, Vienna, Austria). Vaccine acceptance was modeled as a function of (1) age, (2) sex, (3) history of influenza vaccination in the 2019 to 2020 season, (4) job responsibility involving direct patient interaction, (5) concern about COVID-19 infection, (6) self-reported health, and (7) educational attainment. These independent variables were chosen because of their association with vaccine acceptance in prior analyses (gender, influenza vaccination, concern about COVID-19, educational attainment), ${ }^{1-18}$ or because an effect was plausibly expected among health care personnel as determined by our multidisciplinary research team (eg, we hypothesized that persons involved in direct patient interaction would be more likely to accept vaccination due to their greater risk of potential 
occupational exposure to COVID-19 infected persons). Odds ratios, 95\% confidence intervals (CI), and 2-sided $P$ values were calculated for each variable.

Of the 3347 surveys completed, 3292 (98.4\%) had complete data records concerning the 8 regression variables. The 55 records $(1.6 \%)$ that were missing data elements were excluded from the regression analysis. Demographic characteristics of records with missing data elements are shown in Appendix Table 2. Multicollinearity among predictor variables was excluded through the calculation of the variance inflation factor (VIF) for each variable. The maximal VIF was 1.11 , indicating that multicollinearity was not significantly influencing the model fit. Sensitivity analyses to control for the impact of (1) selecting different dichotomization thresholds, (2) discretizing age, or (3) including race in the regression model were also conducted. Post hoc exploratory subgroup analyses were performed for Black, Hispanic, and Asian respondents, who responded less frequently than expected based on their estimated prevalence among the eligible population.

\section{Human Subjects Projection}

The University of Kansas Medical Center Institutional Review Board approved this study. Informed consent was obtained through explanatory text at the beginning of the survey that indicated its purpose, time commitment ( $<5$ minutes), anonymity, voluntary nature, and absence of significant personal benefits or risks. Participants were advised that participation or nonparticipation would not impact academic or employee performance evaluations. All participants were gainfully employed or engaged in higher educational activities at the Medical Center. Their decisional capacity to consent was presumed due to their cognitive capacity to carry out these activities.

\section{Results}

Approximately 18,250 survey invitations were sent and 3,347 individuals participated (18.3\% response rate). Demographic features of respondents are summarized in Table 1. Demographics of respondents are compared with the entire eligible population in Appendix Table 1. Most participants ( $\mathrm{n}=$ $2453 ; 74.4 \%$ ) had a job role involving clinical responsibilities, which were widely distributed between numerous clinical roles (Table 1). About half ( $\mathrm{n}=1823 ; 54.5 \%)$ had roles involving direct patient interactions, of which 807 persons $(44.5 \%$ of those with direct patient interactions) had interacted with a patient known to have COVID-19 (data not shown). Very few respondents had prior diagnosis of COVID-19 ( $\mathrm{n}=54 ; 1.6 \%)$ or positive antibody test $(\mathrm{n}=13,0.4 \%)$. A small fraction of respondents $(\mathrm{n}=38 ; 1.1 \%)$ were already participating in a vaccine trial. Most participants $(n=3123$; 93.5\%) were immunized against influenza in the 2019 to 2020 season (data not shown).

Fully $40.5 \%(\mathrm{n}=1351)$ of respondents intended to delay $(\mathrm{n}=1020 ; 30.6 \%)$ or forgo $(\mathrm{n}=331 ; 9.9 \%)$ vaccination (Table 2). $11.4 \%(\mathrm{n}=379$ ) of respondents intend vaccination during 4 to 6 months, $6.9 \%$ ( $\mathrm{n}=231$ ) during months 7 to 12 , and $12.3 \%$ ( $\mathrm{n}=$ 410) after 1 year or more. Only $59.5 \%(n=1985)$ intend to become immunized within 3 months of regulatory approval $-37.2 \%(\mathrm{n}=1241)$ within the first month and $22.3 \%(\mathrm{n}=744)$ during 1 to 3 months.

Table 3 describes factors associated with intention to receive vaccination within 3 months of approval. Intention to receive early COVID-19 vaccination was more likely in men (adjusted OR [aOR], 2.43; 95\% CI, 2.00-2.95; $P<.001$ ), individuals vaccinated against influenza in the 2019 to 2020 season (aOR, 2.35; 95\% CI, 1.75-3.18; $P<.001)$, persons with extreme or moderate concern about COVID-19 (aOR, 2.40; 95\% CI, 2.07$2.79 ; P<.001)$ and individuals with postgraduate education (aOR, 1.41; 95\% CI, 1.21-1.65; $P<.001)$. Interestingly, we did not detect an association between early COVID-19 vaccine acceptance and (1) age, (2) having a job role involving direct patient interaction, or (3) lower self-reported overall health in either bivariable or multivariable analyses.

We considered that these associations might be detected (or fail to be detected) due to the choices we made for the dichotomization thresholds. To control for this, we performed bivariable and multivariable sensitivity analyses using all possible combinations of alternative dichotomization thresholds: (1) for viral concern, between somewhat or greater and slightly or less; (2) for self-reported health status, between good or greater and fair or worse; (3) for educational attainment, between some college or less and college graduate or more; and (4) for intention to become vaccinated, between within 
Table 1. Respondent Characteristics; $(n=3347)$

\begin{tabular}{|c|c|}
\hline Characteristic & $\mathrm{N}(\%)^{*}$ \\
\hline \multicolumn{2}{|l|}{ Age, years } \\
\hline 18 to 24 & $437(13.1)$ \\
\hline 25 to 34 & $974(29.1)$ \\
\hline 35 to 44 & $709(21.2)$ \\
\hline 45 to 54 & $565(16.9)$ \\
\hline 55 to 64 & $520(15.5)$ \\
\hline 65 years or greater & $142(4.2)$ \\
\hline \multicolumn{2}{|l|}{ Sex } \\
\hline Men & $726(21.8)$ \\
\hline Women & $2601(78.0$ \\
\hline Other & $7(0.2)$ \\
\hline No response & 13 \\
\hline \multicolumn{2}{|l|}{ Race } \\
\hline American Indian or Alaska Native & $6(0.2)$ \\
\hline Asian & $125(3.8)$ \\
\hline Black or African American & $104(3.1)$ \\
\hline White & $2912(87.6$ \\
\hline Native Hawaiian or Other Pacific Islander & $4(0.1)$ \\
\hline Other & $79(2.4)$ \\
\hline Multiple & $95(2.9)$ \\
\hline No response & 22 \\
\hline \multicolumn{2}{|l|}{ Hispanic, Latino, or Spanish Origin } \\
\hline Absent & $3170(95.4)$ \\
\hline Present & $152(4.6)$ \\
\hline No response & 25 \\
\hline \multicolumn{2}{|l|}{ Educational attainment } \\
\hline Some high school or less & $3(0.1)$ \\
\hline High school graduate & $59(1.8)$ \\
\hline Some college & $398(11.9)$ \\
\hline College graduate & $1467(43.9)$ \\
\hline Master's degree & $696(20.8$ \\
\hline Doctorate or professional degree & $716(21.4)$ \\
\hline No response & 8 \\
\hline \multicolumn{2}{|l|}{ Clinical role } \\
\hline No clinical responsibilities & $844(25.6)$ \\
\hline Attending physician & $247(7.5)$ \\
\hline Fellow or resident physician & $79(2.4)$ \\
\hline Advanced practice provider (APRN, PA) & $118(3.6)$ \\
\hline Licensed nurse (RN, LPN) & $491(14.9)$ \\
\hline Clinical pharmacist or pharmacy staff & $81(2.5)$ \\
\hline Physical, occupational, or speech therapy & $117(3.5)$ \\
\hline Unlicensed care aid & $48(1.5)$ \\
\hline Case management or social work & $32(1.0)$ \\
\hline Technician (radiology, EKG, lab draw, etc) & $76(2.3)$ \\
\hline Clinical laboratory or clinical pathology & $52(1.6)$ \\
\hline Administrative or support staff & $300(9.1)$ \\
\hline Medical student & $227(6.9)$ \\
\hline Nursing student & $82(2.5)$ \\
\hline
\end{tabular}

Continued
Table 1. Continued

\begin{tabular}{lr}
\hline Characteristic & $\mathrm{N}(\%)^{*}$ \\
\hline School of health professions student & $153(4.6)$ \\
Other student & $34(1.0)$ \\
Other & $316(9.6)$ \\
No response & 50 \\
\hline
\end{tabular}

APRN, advanced practice registered nurse; PA, physician assistant; RN, registered nurse; LPN, licensed practical nurse; EKG, electrocardiogram

*Percentages refer to all respondents (excluding "no response") for each item.

1 month and 1 month or greater. The results of these sensitivity analyses did not substantively alter our conclusions (see "Sensitivity Analyses" in Appendix and Appendix Tables 3-9).

Factors influencing a decision to delay or forgo vaccination (barriers) were also assessed. Among participants not planning for immediate vaccination, the most common barriers included concerns about (1) long-term side effects $(\mathrm{n}=1197 ; 57.1 \%)$, (2) safety ( $\mathrm{n}=1152 ; 55.0 \%)$, (3) efficacy $(\mathrm{n}=777$; $37.1 \%)$, (4) risk-to-benefit ratio $(\mathrm{n}=650 ; 31.0 \%)$ and $(5)$ cost $(\mathrm{n}=25 ; 12.2 \%)$. The frequencies of additional barriers are shown in Table 2. "Other" barriers were also allowed to be reported as freetext responses. Further barriers identified by this method included, inter alia, concerns about pregnancy, teratogenicity, fertility and breastfeeding; mistrust of government; and desire to allow highrisk individuals access to the vaccine first.

In addition, we evaluated for nonresponse bias. We applied 3 common methods to estimate this bias. ${ }^{29}$ First, a continuum of resistance theory proposes that survey respondents lie along a continuum from early respondents to late respondents to nonrespondents. ${ }^{29}$ Comparisons between early and late respondents ("wave" analysis) may therefore provide some insight into nonresponse bias. ${ }^{29} \mathrm{We}$ produced a diagnostic plot using a 500-respondent rolling window for early ( $<3$ months), late ( $>3$ months), and never vaccination acceptance (Appendix Figure 1). Vaccine acceptance patterns remain essentially stable as a function of respondent order, which is consistent with - but does not definitively establish - the absence of strong nonresponse bias. Second, we performed sensitivity analyses including the survey completion timestamp as a predictor variable (Appendix Tables 10-11). 
Table 2. Intentions, Barriers, and Facilitators Associated with SARS-CoV-2 Vaccination $(\mathrm{n}=3347)$

\begin{tabular}{|c|c|}
\hline Variable & $\mathrm{N}(\%)^{*}$ \\
\hline \multicolumn{2}{|l|}{$\begin{array}{l}\text { If a vaccine for novel coronavirus } \\
\text { (COVID-19) receives Food and Drug } \\
\text { Administration (FDA) approval, } \\
\text { when do you intend to become } \\
\text { vaccinated? }\end{array}$} \\
\hline Within the first month of approval & $1241(37.2$ \\
\hline 1 to 3 months after approval & $744(22.3)$ \\
\hline 4 to 6 months after approval & $379(11.4$ \\
\hline 7 to 12 months after approval & $231(6.9)$ \\
\hline $\begin{array}{l}\text { More than } 1 \text { year (12 months) after } \\
\text { approval }\end{array}$ & $410(12.3)$ \\
\hline I do not intend to be vaccinated & $331(9.9)$ \\
\hline No response & 11 \\
\hline \multicolumn{2}{|l|}{$\begin{array}{l}\text { Which of the following concerns influence } \\
\text { your decision to delay vaccination or to not } \\
\text { receive vaccination? }\end{array}$} \\
\hline Long-term side effects of the vaccine & $1197(57.1)$ \\
\hline The vaccine will not be safe & $1152(55.0)$ \\
\hline The vaccine will not be effective & $777(37.1)$ \\
\hline Risk of vaccination is more than the benefit & $650(31.0)$ \\
\hline The vaccine will be too expensive & $255(12.2$ \\
\hline I may be allergic to the vaccine & $234(11.2$ \\
\hline $\begin{array}{l}\text { Short-term side effects (painful injection, } \\
\text { muscle pain, feeling unwell the day of } \\
\text { the injection, etc.) }\end{array}$ & $159(7.6)$ \\
\hline Personal religious, moral or ethical reasons & $154(7.4)$ \\
\hline $\begin{array}{l}\text { The vaccine will give me novel coronavirus } \\
\text { (COVID-19) }\end{array}$ & $100(4.8)$ \\
\hline I will not have time to get the vaccine & $79(3.8)$ \\
\hline $\begin{array}{l}\text { Already been infected with novel } \\
\text { coronavirus (COVID-19) }\end{array}$ & $48(2.3)$ \\
\hline Other & $303(14.5)$ \\
\hline No response & 24 \\
\hline \multicolumn{2}{|l|}{$\begin{array}{l}\text { How concerned are you about becoming } \\
\text { infected with novel coronavirus } \\
\text { (COVID-19)? }\end{array}$} \\
\hline Extremely concerned & $532(15.9)$ \\
\hline Moderately concerned & $1195(35.7)$ \\
\hline Somewhat concerned & $835(25.0$ \\
\hline Slightly concerned & $554(16.6)$ \\
\hline Not at all concerned & $228(6.8)$ \\
\hline No response & 3 \\
\hline \multicolumn{2}{|l|}{ In general, would you say your health is: } \\
\hline Excellent & $948(28.4)$ \\
\hline Very good & $1651(49.4)$ \\
\hline Good & $641(19.2)$ \\
\hline Fair & $95(2.8)$ \\
\hline Poor & $6(0.2)$ \\
\hline No response & 6 \\
\hline
\end{tabular}

*Percentages refer to all respondents (excluding "no response") for each item.

${ }^{\dagger}$ Queried of all persons not reporting intention to become vaccinated within the first month. Percentages may not sum to $100 \%$ because respondents may report multiple concerns.
Survey timestamp is nonsignificant in all models and does not robustly alter the conclusions of the prior multivariable analysis. Third, a comparison of the demographic profile of survey respondents to estimates of the eligible population (Appendix Table 1) suggests that survey responses broadly reflect a meaningful, representative cross-section of the relevant population with one clear exception: Black-identifying individuals were under-sampled (3.1\%) due to lower response rate in this subgroup, relative to their estimated population prevalence (12.9\%).

Post hoc exploratory subgroup analysis of Black respondents ( $\mathrm{n}=126$ including persons who specify more than 1 race; Table 4) revealed that only 31 Black respondents (24.8\%) intend to become vaccinated within the first 3 months, far less than the rate among all respondents (59.5\%; proportional Z-test $P<.001)$. Moreover, post hoc sensitivity analyses, including a regression term for 4-level race (White, $\mathrm{n}=2873$; Black or African American, $\mathrm{n}=103$; Asian, $\mathrm{n}=124$; or Other/Multiple, $\mathrm{n}=173$; Appendix Table 12-14) reveal a robust association between Black racial identity and decreased vaccination acceptance at both 1 month (aOR, 0.20; 95\% CI, $0.10-0.35 ; P<.001)$ and 3 months $(\mathrm{aOR}$, $0.13 ; 95 \%$ CI, $0.08-0.21 ; P<.001)$. Significant associations between male sex, prior influenza vaccination, greater concern about COVID-19, and higher education were preserved in the race-inclusive model. Barriers to vaccination among Black individuals nevertheless largely mirror the pattern seen in the full sample, viz.: long-term-side effects $(\mathrm{n}=69 ; 63.9 \%)$, safety $(\mathrm{n}=64 ; 59.3 \%)$, risk-to-benefit ratio $(\mathrm{n}=40 ; 37.0 \%)$ and efficacy $(\mathrm{n}=38$; $35.2 \%$ ). Similar post hoc exploratory subgroup analyses for Hispanic and Asian respondents are presented in Table 4.

\section{Discussion}

Many COVID-19 vaccines are being concurrently developed to address the ongoing COVID-19 pandemic, but evidence suggests enthusiasm for COVID-19 vaccination among the general public may be limited. ${ }^{10-12}$ Data before this study are lacking for HCP.

The attitude and behavior of HCP toward COVID-19 vaccination are specifically important because (1) HCP are at increased risk of COVID$19,{ }^{9}$ (2) infected HCP risk transmitting COVID-19 
Table 3. Bivariable and Multivariable Logistical Regression Models for Intention to Receive CoVID-19 Within 3 Months of Regulatory Approval

\begin{tabular}{|c|c|c|c|c|c|}
\hline \multirow[b]{2}{*}{ Variable } & \multicolumn{2}{|c|}{ Bivariable (Crude) } & \multicolumn{3}{|c|}{ Multivariable (Adjusted) } \\
\hline & cOR $(95 \% \mathrm{CI})$ & $P$ Value & aOR (95\% CI) & $P$ Value & Significance* \\
\hline Age, decades & $1.02(0.97-1.07)$ & .548 & $0.95(0.90-1.00)$ & .054 & \\
\hline $\mathrm{Men}^{\dagger}$ & $2.39(1.99-2.89)$ & $<.001$ & $2.43(2.00-2.95)$ & $<.001$ & $* * *$ \\
\hline Influenza vaccine $e^{\ddagger}$ & $2.37(1.79-3.15)$ & $<.001$ & $2.35(1.75-3.18)$ & $<.001$ & $* * *$ \\
\hline Viral concern ${ }^{\S}$ & $2.30(1.99-2.65)$ & $<.001$ & $2.40(2.07-2.79)$ & $<.001$ & $* * *$ \\
\hline Patient interaction" & $0.97(0.85-1.12)$ & .704 & $0.92(0.79-1.07)$ & .282 & \\
\hline Higher education ${ }^{\pi}$ & $1.62(1.40-1.87)$ & $<.001$ & $1.41(1.21-1.65)$ & $<.001$ & $* * *$ \\
\hline Poor health** & $0.87(0.74-1.03)$ & .115 & $0.85(0.71-1.01)$ & .065 & \\
\hline \multicolumn{6}{|l|}{ Race $^{\dagger \dagger}$} \\
\hline White & Reference & - & - & - & - \\
\hline Black & $0.16(0.10-0.25)$ & $<.001$ & - & - & - \\
\hline Asian & $1.53(1.04-2.29)$ & .036 & - & - & - \\
\hline Other/multiple & $0.63(0.47-0.86)$ & .003 & - & - & - \\
\hline Hispanic $^{\dagger \dagger}$ & $0.97(0.70-1.36)$ & .873 & - & - & - \\
\hline
\end{tabular}

cOR, crude odds ratio; CI, confidence interval; aOR, adjusted odds ratio.

${ }^{*}$ Significance with respect to the multivariable model $\left({ }^{*} P<.05,{ }^{* *} P<.01,{ }^{* *} P<.001\right)$.

${ }^{\dagger}$ Self-reported sex.

${ }^{\ddagger}$ Completion of influenza vaccination in the 2019-2020 season.

\$"Extremely concerned" or "moderately concerned" about becoming infected with COVID-19 on a 5-point Likert scale.

"Job responsibility involving direct patient interaction.

"Master's degree or Doctorate/Professional.

** Reporting anything other than "Excellent" or "Very Good" health on a 5-point Likert scale.

${ }^{\dagger+}$ - Not included in the multivariable model.

to patients and their family members, and (3) HCP potentially serve as role models of appropriate preventive health behavior by the general public. Widespread HCP refusal of COVID-19 immunization may signal danger to the general public. This could imperil the overall efficacy of the mass vaccination efforts that will be necessary to confer herd immunity among the public. Barriers to vaccine uptake among HCP must therefore be addressed vigorously.

We found that fully $40.5 \%$ of personnel at a large tertiary care medical center will delay $(30.6 \%)$ or forgo $(9.9 \%)$ vaccination following regulatory approval; only $59.5 \%$ will accept vaccination within 3 months. The intended non-vaccination rate for COVID-19 (9.9\%) is similar to that reported for influenza in the 2019 to 2020 season (6.5\%). The main factors limiting vaccination uptake are concerns about long-term side effects, safety, efficacy, risk-to-benefit ratio, and cost. Those planning to delay, but not forgo, vaccination thus seem to require high-quality, post-approval surveillance data to inform their decision to proceed with immunization.
Multivariable analyses indicate vaccine acceptance is greatest among persons with (1) male sex, (2) previous influenza vaccination, (3) high concern about COVID-19, and (4) high educational attainment. Black respondents were much less likely than all respondents to report intention to become vaccinated within 3 months and over a quarter (28.8\%) intend to forgo vaccination completely. This may reflect mistrust of medical personnel in general, ${ }^{30-32}$ but may also be exacerbated by under-representation of minorities in COVID-19 related clinical trials. $^{33}$

Our data are concordant with prior analyses of the general public and HCPs which showed associations between vaccine acceptance and male sex, ${ }^{11,13,20,21,23}$ prior influenza vaccination, ${ }^{12,13,21,23,34}$ concern about COVID-19, ${ }^{15,20,21,23,34}$ and educational attainment. ${ }^{11,12,35}$ The factors driving the association between male sex and greater COVID-19 vaccine acceptance are unclear; however, we note that males have a significantly high risk of COVID19-related intensive care unit admission and death than females. ${ }^{36}$ Contrary to our expectations and at variance with a recent study of Hong Kong 


\begin{tabular}{|c|c|c|c|c|}
\hline \multirow[b]{2}{*}{ Variable } & \multicolumn{4}{|c|}{$\mathrm{N}(\%)^{*}$} \\
\hline & White & Black & Hispanic & Asian \\
\hline \multicolumn{5}{|l|}{$\begin{array}{l}\text { If a vaccine for novel coronavirus (COVID-19) receives Food } \\
\text { and Drug Administration (FDA) approval, when do you } \\
\text { intend to become vaccinated? }\end{array}$} \\
\hline Within the first month of approval & $1152(38.5)$ & $17(13.6)$ & $56(37.1)$ & $61(40.1)$ \\
\hline 1 to 3 months after approval & $675(22.6)$ & $14(11.2)$ & $34(22.5)$ & $44(28.9)$ \\
\hline 4 to 6 months after approval & $333(11.1)$ & $12(9.6)$ & $19(12.6)$ & $20(13.2)$ \\
\hline 7 to 12 months after approval & $197(6.6)$ & $17(13.6)$ & $13(8.6)$ & $9(5.9)$ \\
\hline More than 1 year (12 months) after approval & $355(11.9)$ & $29(23.2)$ & $18(11.9)$ & $16(10.5)$ \\
\hline I do not intend to be vaccinated & $278(9.3)$ & $36(28.8)$ & $11(7.3)$ & $2(1.3)$ \\
\hline No response & 10 & 1 & 1 & 0 \\
\hline \multicolumn{5}{|l|}{$\begin{array}{l}\text { Which of the following concerns influence your decision to } \\
\text { delay vaccination or to not receive vaccination? }\end{array}$} \\
\hline The vaccine will not be safe & $1015(55.2)$ & $64(59.3)$ & $37(38.9)$ & $56(61.5)$ \\
\hline The vaccine will not be effective & $693(37.7)$ & $38(35.2)$ & $34(35.8)$ & $29(31.9)$ \\
\hline I may be allergic to the vaccine & $186(10.1)$ & $23(21.3)$ & $4(4.2)$ & $18(19.8)$ \\
\hline Risk of vaccination is more than the benefit & $568(30.9)$ & $40(37.0)$ & $25(26.3)$ & $24(26.4)$ \\
\hline $\begin{array}{l}\text { Short-term side effects (painful injection, muscle pain, feeling } \\
\text { unwell the day of the injection, etc.) }\end{array}$ & $129(7.0)$ & $18(16.7)$ & $4(4.2)$ & $11(12.1)$ \\
\hline Long-term side effects of the vaccine & $1052(57.2)$ & $69(63.9)$ & $49(51.6)$ & $43(47.3)$ \\
\hline The vaccine will be too expensive & $229(12.5)$ & $8(7.4)$ & $15(15.8)$ & $15(16.5)$ \\
\hline I will not have time to get the vaccine & $69(3.8)$ & $0(0.0)$ & $9(9.5)$ & $5(5.5)$ \\
\hline The vaccine will give me novel coronavirus (COVID-19) & $81(4.4)$ & $16(14.8)$ & $5(5.3)$ & $3(3.3)$ \\
\hline Personal religious, moral or ethical reasons & $124(6.7)$ & $21(19.4)$ & $3(3.2)$ & $3(3.3)$ \\
\hline Already been infected with novel coronavirus (COVID-19) & $45(2.4)$ & $2(1.9)$ & $0(0.0)$ & $1(1.1)$ \\
\hline Other & $266(14.5)$ & $16(14.8)$ & $4(4.2)$ & $11(12.1)$ \\
\hline
\end{tabular}

*Percentages refer to all respondents (excluding "no response") for each item.

${ }^{\dagger}$ Queried of all persons not reporting intention to become vaccinated within the first month. Percentages do not sum to $100 \%$ because respondents may report multiple concerns.

nurses $^{25}$ - we did not find evidence that job role involving direct patient interaction increases vaccination acceptance. In addition, that same study ${ }^{25}$ showed that HCP with chronic medical problems were more likely to accept vaccination, but we did not find an association between vaccine acceptance and poor self-reported health.

Major concerns centered on vaccine safety, efficacy, and long-term side effects. Regulatory authorities must assure HCP (and the general public) that forthcoming vaccines are safe and effective by considering high-quality evidence through a rigorous and impartial process. The FDA has now granted emergency use authorization to $2 \mathrm{mRNA}$ vaccines after a thorough review of Phase 3 trial results and manufacturing quality data. ${ }^{5-8}$ Local and national institutions should develop evidence-based educational materials that address these barriers, to allow their workforce to make informed vaccination decisions.

Cost was the fifth most commonly reported barrier. We did not collect information on financial wellbeing because of the concern that it would negatively influence the response rate. However, low-income individuals are the most likely to be cost-sensitive. The Centers for Disease Control and Prevention have committed that "vaccine doses purchased with US taxpayer dollars will be given to the American people at no cost." ${ }^{\text {}}$ Health systems should promulgate messages to their workforce that vaccination will be provided free-of-charge. If public funding of vaccination ceases in the future, health systems should adopt policies that address vaccination costs equitably to avoid exacerbating underlying workforce health disparities. 
This study has limitations. First, data were collected at a single center. These results likely generalize to other academic medical centers or large community hospitals that are socially and demographically similar but may not generalize well to rural areas or small community hospitals. Second, we used a written electronic survey rather than an in-person interviewer. Participants were required to use their best judgment in interpreting the meaning of questions and their responses, without the ability to easily clarify a misinterpretation. Third, the survey is observational and nonrandomized which allows for the possibility of nonresponse bias. Respondents with stronger views on COVID19 vaccination may have been more likely to respond to the survey. Our response rate was $18.3 \%$. High response rates are thought to reduce the likelihood of nonresponse bias in survey studies. ${ }^{29}$ Large unsolicited surveys (eg, those conducted by Pew Research ${ }^{38}$ ) commonly have lower response rates ( $5 \%$ to $15 \%$ ). Lower response rates are not intrinsically bad, except insofar as they increase the risk of nonresponse bias. We failed to find evidence of nonresponse bias in vaccine acceptance (Appendix Figure 1) or the multivariable analysis (Appendix Tables 10-11). There is evidence, however, of nonrespondent bias among eligible Black participants. Black participants reported similar barriers to vaccination but were less likely to accept vaccination. Low response rate of Black participants thus likely results in an underestimate of the total proportion of HCP who intend to delay or forgo vaccination. Further research on minority attitudes toward COVID-19 vaccination - using community-based participatory methods that include black HCP and other health system personnel in the study design - is urgently needed. Fourth, we report an overview of perceived barriers to vaccination, without evaluating cognitive factors that influence participant's assessments of risks and benefits. Further analyses that specifically interrogate participant's risk-benefit analyses should be conducted. Such analyses should specifically consider cognitive risk assessment and decision-making theories that have been previously used to predict vaccination behavior, ${ }^{39}$ such as the health belief model, ${ }^{40}$ the theory of planned behavior, ${ }^{41}$ or prospect theory. ${ }^{42}$ Fifth, our survey included 11 possible barriers to vaccination, but these are certainly not an exhaustive list of all possible barriers. For example, participants might consider the risk level of their family members and close contacts, the timing of vaccination for their family, and specific comorbidities in their decision-making process. Vaccineor trial-specific factors may also affect decisionmaking about specific vaccines: whether or not a vaccine results in viral shedding, how the vaccine trials were conducted, and the length of follow-up in vaccine trials. Analyses with a different design (eg, focus groups) would be helpful to more fully define the range of barriers to vaccination. Sixth, at the time the survey was conducted, it was unclear which (if any) vaccines would receive approval soon. We, therefore, did not include any information about the specific properties of a vaccine or the trial designs. Educational material about some specific trial designs may nevertheless have utility; for example, information about the length of follow-up during the trial may help address concerns about the likelihood of long-term side effects of a given vaccine.

In summary, many (40.5\%) HCPs intend to delay or refuse COVID-19 vaccination. Policymakers at the local, health system, and national levels, should be prepared to address concerns about vaccine safety, efficacy, and cost through the communication of rigorously and impartially evaluated high-quality scientific evidence. Additional work to further investigate beliefs and attitudes - and to address barriers among racial and ethnic minorities will be essential to promote vaccine uptake and public health during the COVID-19 pandemic.

To see this article online, please go to: http://jabfm.org/content/ 34/3/498.full.

\section{References}

1. Dong E, Du H, Gardner L. An interactive webbased dashboard to track COVID-19 in real time. Lancet Infect Dis 2020;20:533-4.

2. Graham BS. Rapid COVID-19 vaccine development. Science 2020;368:945-6.

3. O'Callaghan KP, Blatz AM, Offit PA. Developing a SARS-CoV-2 vaccine at warp speed. JAMA 2020; 324:437.

4. US Department of Health and Human Services. Fact Sheet: Explaining Operation Warp Speed. Available from: https://www.hhs.gov/about/news/ 2020/06/16/fact-sheet-explaining-operation-warpspeed.html. Published 2020. Accessed September 4, 2020.

5. Polack FP, Thomas SJ, Kitchin N, et al. C4591001 Clinical Trial Group. Safety and efficacy of the BNT162b2 mRNA Covid-19 vaccine. N Engl J Med 2020;383:2603-15. 
6. Baden LR, El Sahly HM, Essink B, et al. Efficacy and safety of the mRNA-1273 SARS-CoV-2 vaccine. N Engl J Med 2021;384:403-16.

7. Hinton D. Food and Drug Administration. ModernaTX COVID-19 Vaccine Emergency Use Letter of Authorization. Available from: https:// www.fda.gov/media/144636/download. Published 2020. Accessed January 1, 2021.

8. Hinton D. Food and Drug Administration. Pfizer BioNTech COVID-19 Vaccine Emergency Use Letter of Authorization. Available from: https:// www.fda.gov/media/144412/download. Published 2020. Accessed January 1, 2021.

9. Nguyen LH, Drew DA, Graham MS, et al. Risk of COVID-19 among front-line health-care workers and the general community: a prospective cohort study. Lancet Public Health 2020;5:e475-83.

10. O'Keefe S. One in Three Americans Would Not Get COVID-19 Vaccine. Gallup News. Available from: https://news.gallup.com/poll/317018/onethree-americans-not-covid-vaccine.aspx. Published 2020. Accessed September 4, 2020.

11. Malik AA, McFadden SM, Elharake J, et al. Determinants of COVID-19 vaccine acceptance in the US. EClin Med 2020;26:100495.

12. Fisher KA, Bloomstone SJ, Walder J, et al. Attitudes toward a potential SARS-CoV-2 Vaccine: a survey of U.S. adults. Ann Intern Med 2020; 173:964-73.

13. Hursh SR, Strickland JC, Schwartz LP, et al. Quantifying the impact of public perceptions on vaccine acceptance using behavioral economics. Front Public Health 2020;8:608852.

14. Qiao S, Friedman DB, Tam CC, Zeng C, Li X. Vaccine acceptance among college students in South Carolina: do information sources and trust in information make a difference? Preprint. medRxiv 2020;2020.12.02.20242982.

15. Qiao S, Tam CC, Li X. Risk exposures, risk perceptions, negative attitudes toward general vaccination, and COVID-19 vaccine acceptance among college students in South Carolina. Preprint. medRxiv 2020;2020.11.26.20239483.

16. Kreps S, Prasad S, Brownstein JS, et al. Factors associated with US adults' likelihood of accepting COVID-19 vaccination. JAMA Netw Open 2020;3: e2025594.

17. Pogue K, Jensen JL, Stancil CK, et al. Influences on attitudes regarding potential COVID-19 vaccination in the United States. Vaccines (Basel) 2020; 8:582.

18. Aoyagi Y, Beck CR, Dingwall R, et al. Healthcare workers' willingness to work during an influenza pandemic: a systematic review and meta-analysis. Influenza Other Respir Viruses 2015;9:120-30.

19. Wang TL, Jing L, Bocchini JA, Jr. Mandatory influenza vaccination for all healthcare personnel: a review on justification, implementation and effectiveness. Curr Opin Pediatr 2017;29:606-15.

20. Detoc M, Bruel S, Frappe P, et al. Intention to participate in a COVID-19 vaccine clinical trial and to get vaccinated against COVID-19 in France during the pandemic. Vaccine 2020;38:7002-6.

21. Gagneux-Brunon A, Detoc $M$, Bruel S, et al. Intention to get vaccinations against COVID-19 in French healthcare workers during the first pandemic wave: a cross sectional survey. J Hosp Infect 2020;108:168-73.

22. Lazarus JV, Ratzan SC, Palayew A, et al. A global survey of potential acceptance of a COVID-19 vaccine. Nat Med 2020;1-4.

23. Kabamba Nzaji M, Kabamba Ngombe L, Ngoie Mwamba G, et al. Acceptability of vaccination against COVID-19 among healthcare workers in the Democratic Republic of the Congo. Pragmat Obs Res 2020;11:103-9.

24. Kwok KO, Li KK, Wei WI, et al. Influenza vaccine uptake, COVID-19 vaccination intention and vaccine hesitancy among nurses: a survey. Int J Nurs Stud 2021;114:103854.

25. Wang K, Wong ELY, Ho KF, et al. Intention of nurses to accept coronavirus disease 2019 vaccination and change of intention to accept seasonal influenza vaccination during the coronavirus disease 2019 pandemic: a cross-sectional survey. Vaccine 2020;38:7049-56.

26. Harris PA, Taylor R, Minor BL, et al.. REDCap Consortium. The REDCap consortium: building an international community of software platform partners. J Biomed Inform 2019;95:103208.

27. Harris PA, Taylor R, Thielke R, et al. Research electronic data capture (REDCap)-a metadatadriven methodology and workflow process for providing translational research informatics support. J Biomed Inform 2009;42:377-81.

28. Ware JE, Jr., Sherbourne CD. The MOS 36-item short-form health survey (SF-36). I. Conceptual framework and item selection. Med Care 1992;30: 473-83.

29. Lewis EF, Hardy M, Snaith B. Estimating the effect of nonresponse bias in a survey of hospital organizations. Eval Health Prof 2013;36:330-51.

30. Boulware LE, Cooper LA, Ratner LE, et al. Race and trust in the health care system. Public Health Rep 2003;118:358-65.

31. Doescher MP, Saver BG, Franks P, et al. Racial and ethnic disparities in perceptions of physician style and trust. Arch Fam Med 2000;9:1156-63.

32. Halbert $\mathrm{CH}$, Armstrong $\mathrm{K}$, Gandy $\mathrm{OH}, \mathrm{Jr}$., et al. Racial differences in trust in health care providers. Arch Intern Med 2006;166:896-901.

33. Chastain DB, Osae SP, Henao-Martínez AF, et al. Racial disproportionality in Covid clinical trials. N Engl J Med 2020;383:e59. 
34. Sherman SM, Smith LE, Sim J, et al. COVID-19 vaccination intention in the UK: results from the COVID-19 vaccination acceptability study (CoVAccS), a nationally representative cross-sectional survey. Hum Vaccin Immunother 2020;1-10.

35. Al-Mohaithef M, Padhi BK. Determinants of COVID-19 vaccine acceptance in Saudi Arabia: a web-based national survey. JMDH 2020;13: 1657-63.

36. Peckham H, de Gruijter NM, Raine C, et al. Male sex identified by global COVID-19 meta-analysis as a risk factor for death and ITU admission. Nat Commun 2020;11:6317.

37. Centers for Disease Control and Prevention. 8 Things to Know about the U.S. COVID-19 Vaccination Program. Available from: https://www. cdc.gov/coronavirus/2019-ncov/vaccines/8-things. html. Published 2021. Accessed January 10, 2021.

38. Pew Research Center. U.S. Survey Research: Our Survey Methodology in Detail. Available from: https://www.pewresearch.org/methods/u-s-surveyresearch/our-survey-methodology-in-detail/. Accessed September 18, 2020.

39. Myers KL. Predictors of maternal vaccination in the United States: an integrative review of the literature. Vaccine 2016;34:3942-9.

40. Rosenstock IM. Historical origins of the health belief model. Health Educ Quart 1974;2:328-35.

41. Ajzen I. The theory of planned behavior. Organ Behav Hum Dec 1991;50:179-211.

42. Kahneman D, Tversky A. Prospect theory: an analysis of decision under risk. Econometrica 1979;47:263-91. 


\section{Appendix:}

Acceptance of COVID-19 vaccination among health system personnel

[Sensitivity Analyses]

For intention to receive vaccination within 3 months (primary outcome), alternatively thresholding any predictor variable did not change the interpretation of results in bivariable analyses (Appendix Table 3) analyses. For multivariable analysis analyses (Appendix Table 4), the interpretation of results also did not change for any combination of predictor variable thresholds, except that in 1 threshold combination (original concern, original education, alternative health status) age became a marginally significant predictor variable $(\mathrm{aOR}, 0.94 ; 95 \% \mathrm{CI}, 0.89-1.00 ; P=$ .036). Age was nonsignificant in the bivariable case and all other threshold combinations. For intention to receive vaccination within 1 month (alternative threshold for primary outcome), bivariable analyses (Appendix Table 5) showed a new marginally significant association with job role involving direct patient interaction (crude OR [cOR], 1.17; 95\% CI, 1.011.34; $P=.034)$. This association did not persist $(P>.05)$ in any multivariable analyses (Appendix Table 6) using all possible combinations of original and alternative predictor variables except in the case where original concern, original education, and alternative health status thresholds were used. In this case only, job role involving direct patient interaction was again marginally significant (aOR, 1.17; 95\% CI, $1.00-1.36 ; \quad P=.047)$. We thus conclude that associations between intention to receive early COVID-19 vaccination and male gender, prior influenza vaccination, higher concern about COVID-19, and higher educational attainment are robust against changes in the analysis method. We cannot fully exclude a weak association between age and early ( $<3$ months) vaccination intention or between job role involving direct patient interaction and very early $(<1$ month) vaccination intention.

We also considered that age might influence vaccine intention nonlinearly. To that end, we performed 4-level, quantile discretization of age (age less than 30 years; $n=924$; age 30 to 39 years, $n=846$; age 40 to 54 years, $\mathrm{n}=872$; and age 55 years or greater, $\mathrm{n}=650$ ) and repeated the sensitivity analyses. The conclusions that male gender, prior influenza vaccination, elevated concern about COVID-19, and greater educational attainment - but not direct patient interaction or selfreported health - influence vaccination acceptance remain robust to this variation in the analysis. Bivariable analyses did not reveal a relationship between 4-level age and vaccination intention at 1 or 3 months (Appendix Table 7). Multivariable analyses (Appendix Tables 8 and 9) suggested that persons aged 30 to 54 years - but not persons older than 54 years - had reduced likelihood to obtain vaccination by 3 months, but not at 1 month (alternative threshold for primary outcome). Because of this sensitivity to details of the analysis method, we are thus hesitant to assert that a nonlinear association between age and vaccination intention can be inferred from the available data. 
Appendix Figure 1. Vaccine acceptance as a function of respondent order. The proportion of respondents reporting early ( $<3$ months), late ( $>3$ months), and never vaccine acceptance within 500-participant rolling windows is shown. Earlier respondents seem on the left while later respondents seem on the right. Rolling averages are compared with the whole-sample averages (solid lines). Vaccine acceptance patterns remain essentially stable as a function of respondent order, which is consistent with - but does not definitively establish - the absence of strong nonresponse bias.

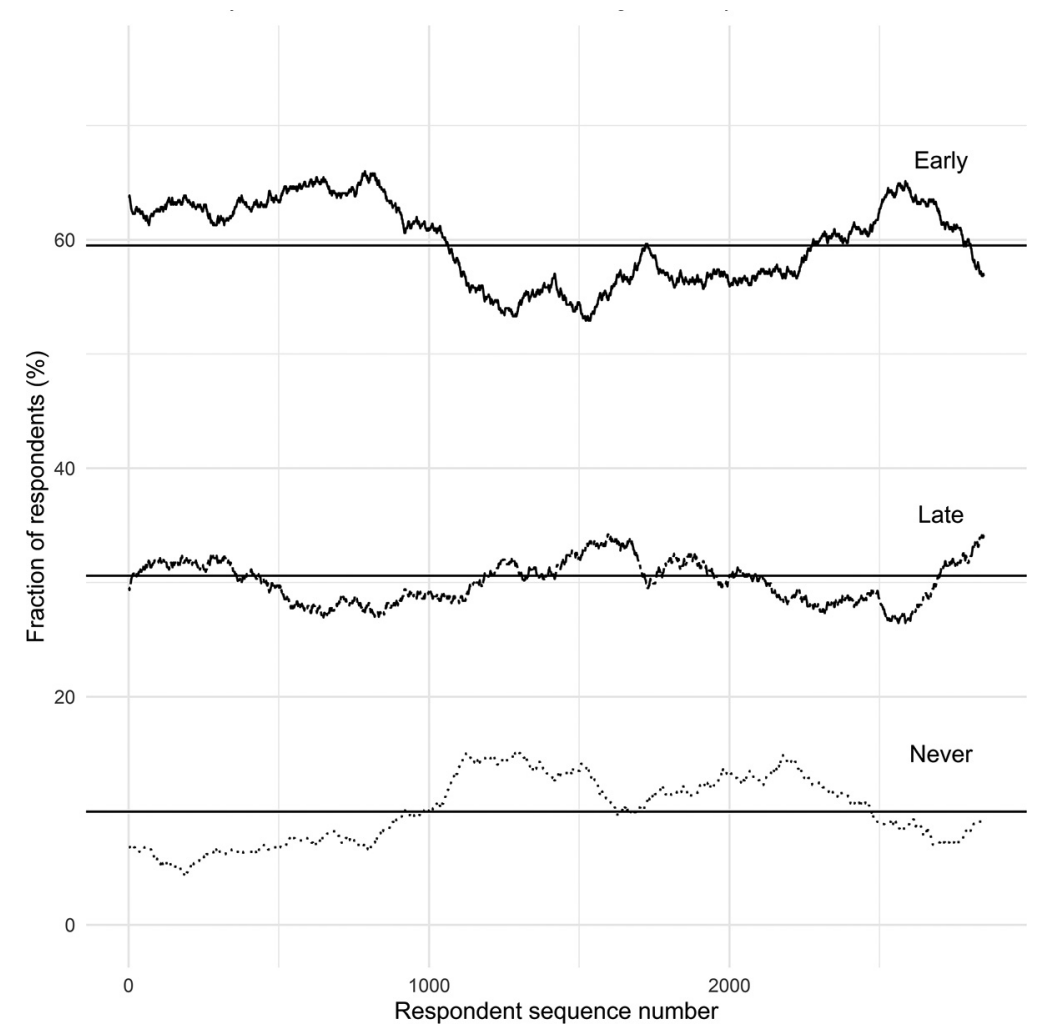




\begin{tabular}{|c|c|c|c|c|}
\hline & \multicolumn{4}{|c|}{$\mathbf{N}(\%)^{*}, \dagger$} \\
\hline & Survey & Health System ${ }^{\ddagger}$ & University $^{\ddagger}$ & Composite ${ }^{\S}$ \\
\hline \multicolumn{5}{|l|}{ Age, years } \\
\hline 18 to 24 & $437(13.1)$ & $1153(9.9)$ & $1334(18.7)$ & $2487(13.3)$ \\
\hline 25 to 34 & $974(29.1)$ & $4054(34.8)$ & $2763(38.8)$ & $6817(36.3)$ \\
\hline 35 to 44 & $709(21.2)$ & $2667(22.9)$ & $1362(19.1)$ & $4029(21.5)$ \\
\hline 45 to 54 & $565(16.9)$ & $1887(16.2)$ & $812(11.4)$ & $2699(14.4)$ \\
\hline 55 to 64 & $520(15.5)$ & $1572(13.5)$ & $628(8.8)$ & $2200(11.7)$ \\
\hline 65 years or greater & $142(4.2)$ & $315(2.7)$ & $221(3.1)$ & $536(2.9)$ \\
\hline \multicolumn{5}{|l|}{ Sex } \\
\hline Men & $726(21.8)$ & $2225(19.1)$ & $2912(40.9)$ & $5137(27.4)$ \\
\hline Women & $2601(78.0)$ & $9423(80.9)$ & $4208(59.1)$ & $13631(72.6)$ \\
\hline Other & $7(0.2)$ & - & - & - \\
\hline No response & 13 & - & - & - \\
\hline \multicolumn{5}{|l|}{ Race $^{\|}$} \\
\hline American Indian or Alaska Native & $6(0.2)$ & $57(0.5)$ & $24(0.4)$ & $81(0.4)$ \\
\hline Asian/Pacific Islander & $129(3.9)$ & $399(3.4)$ & $635(9.6)$ & $1034(5.7)$ \\
\hline Black or African American & $104(3.1)$ & $2007(17.2)$ & $353(5.3)$ & $2360(12.9)$ \\
\hline White & $2912(87.6)$ & $8555(73.4)$ & $5241(78.9)$ & $13796(75.4)$ \\
\hline Other & $79(2.4)$ & $339(2.9)$ & $136(2.0)$ & $475(2.6)$ \\
\hline Multiple & $95(2.9)$ & $291(2.5)$ & $250(3.8)$ & $541(3.0)$ \\
\hline No response & 22 & - & 481 & 481 \\
\hline \multicolumn{5}{|l|}{ Hispanic, Latino, or Spanish Origin } \\
\hline Present & $152(4.6)$ & $769(6.6)$ & $370(5.2)$ & $1139(6.1)$ \\
\hline Absent & $3170(95.4)$ & $10879(93.4)$ & $6750(94.8)$ & $17629(93.9)$ \\
\hline No response & 25 & - & - & - \\
\hline Total & 3347 & 11648 & 7120 & 18768 \\
\hline
\end{tabular}

*The count $(\mathrm{N})$ of individuals in each demographic category are actual counts for the survey and University populations. Health System counts are calculated from the reported percentages and a total of 11,648 employees.

†Percentages are calculated from the number of responses for each category (excluding "no response").

${ }^{\ddagger}$ Health system demographic statistics are provided by the University of Kansas Health System Human Resources Department, and as current as of 2020. University demographic statistics are provided by the University of Kansas Health Medical Center Office of Enterprise Analytics and are also current as of 2020. Health System and University populations are not completely disjoint (eg, a University faculty physician may also be a member of the Health System medical staff) but this represents a minority of both populations.

${ }^{\S}$ Composite is a combination of Health System and University demographics to approximate the demographic features of the whole underlying eligible population.

"Race and ethnicity data are reported here as orthogonal demographic features (ie, Hispanic persons may be of any race). Health system and University race and ethnicity data were reported with Hispanic, Latino, or Spanish origin as a racial category rather than two separate features for race and ethnicity. For the health system and University data, Hispanic/Latino persons were assumed to have racial distributions similar to their national distribution for Hispanic persons: $1.4 \%$ American Indian or Alaska Native, $0.5 \%$ Asian or Pacific Islander, 2.5\% Black or African American, $53.0 \%$ white, 36.7\% other, and 6.0\% multiple races (these proportions do not sum to $100 \%$ due to rounding). 
Appendix Table 2. Demographic Features of Records Excluded From Regression Analysis

\begin{tabular}{|c|c|}
\hline Demographic & $\mathrm{N}(\%)^{*}$ \\
\hline \multicolumn{2}{|l|}{ Age, years } \\
\hline 18 to 24 & $5(9.1)$ \\
\hline 25 to 34 & $17(30.9)$ \\
\hline 35 to 44 & $10(18.2)$ \\
\hline 45 to 54 & $11(20.0)$ \\
\hline 55 to 64 & $9(16.4)$ \\
\hline 65 years or greater & $3(5.5)$ \\
\hline \multicolumn{2}{|l|}{ Sex } \\
\hline Men & $2(4.8)$ \\
\hline Women & $33(78.6)$ \\
\hline Other & $7(16.7)$ \\
\hline No response & 13 \\
\hline \multicolumn{2}{|l|}{ Race } \\
\hline American Indian or Alaska Native & - \\
\hline Asian & $1(2.2)$ \\
\hline Black or African American & $1(2.2)$ \\
\hline White & $39(84.8)$ \\
\hline Native Hawaiian or Other Pacific Islander & - \\
\hline Other & 4 \\
\hline Multiple & 1 \\
\hline No response & 9 \\
\hline \multicolumn{2}{|l|}{ Hispanic, Latino, or Spanish Origin } \\
\hline Absent & $46(95.8)$ \\
\hline Present & $2(4.2)$ \\
\hline No response & 7 \\
\hline \multicolumn{2}{|l|}{ Educational attainment } \\
\hline Some high school or less & - \\
\hline High school graduate & $2(4.3)$ \\
\hline Some college & $3(6.4)$ \\
\hline College graduate & $23(48.9)$ \\
\hline Master's degree & $12(25.5)$ \\
\hline Doctorate or professional degree & $7(14.9)$ \\
\hline No response & 8 \\
\hline \multicolumn{2}{|l|}{ Clinical role } \\
\hline No clinical responsibilities & $11(20.4)$ \\
\hline Attending physician & $2(3.7)$ \\
\hline Fellow or resident physician & $3(5.6)$ \\
\hline Advanced practice provider (APRN, PA) & $1(1.9)$ \\
\hline Licensed nurse (RN, LPN) & $15(27.8)$ \\
\hline Clinical pharmacist or pharmacy staff & $1(1.9)$ \\
\hline Physical, occupational, or speech therapy & $1(1.9)$ \\
\hline Unlicensed care aid & $1(1.9)$ \\
\hline Case management or social work & - \\
\hline Technician (radiology, EKG, lab draw, etc) & $3(5.6)$ \\
\hline Clinical laboratory or clinical pathology & $2(3.7)$ \\
\hline Administrative or support staff & $5(9.3)$ \\
\hline Medical student & $2(3.7)$ \\
\hline Nursing student & $2(3.7)$ \\
\hline
\end{tabular}

Continued
Appendix Table 2. Continued

\begin{tabular}{lc}
\hline Demographic & $\mathrm{N}(\%)^{*}$ \\
\hline School of health professions student & - \\
Other student & - \\
Other & $5(9.3)$ \\
No response & 1 \\
\hline
\end{tabular}

APRN, advanced practice registered nurse; PA, physician assistant; RN, registered nurse; LPN, licensed practical nurse; EKG, electrocardiogram.

*Percentages refer to all respondents (excluding "no response") for each item. 


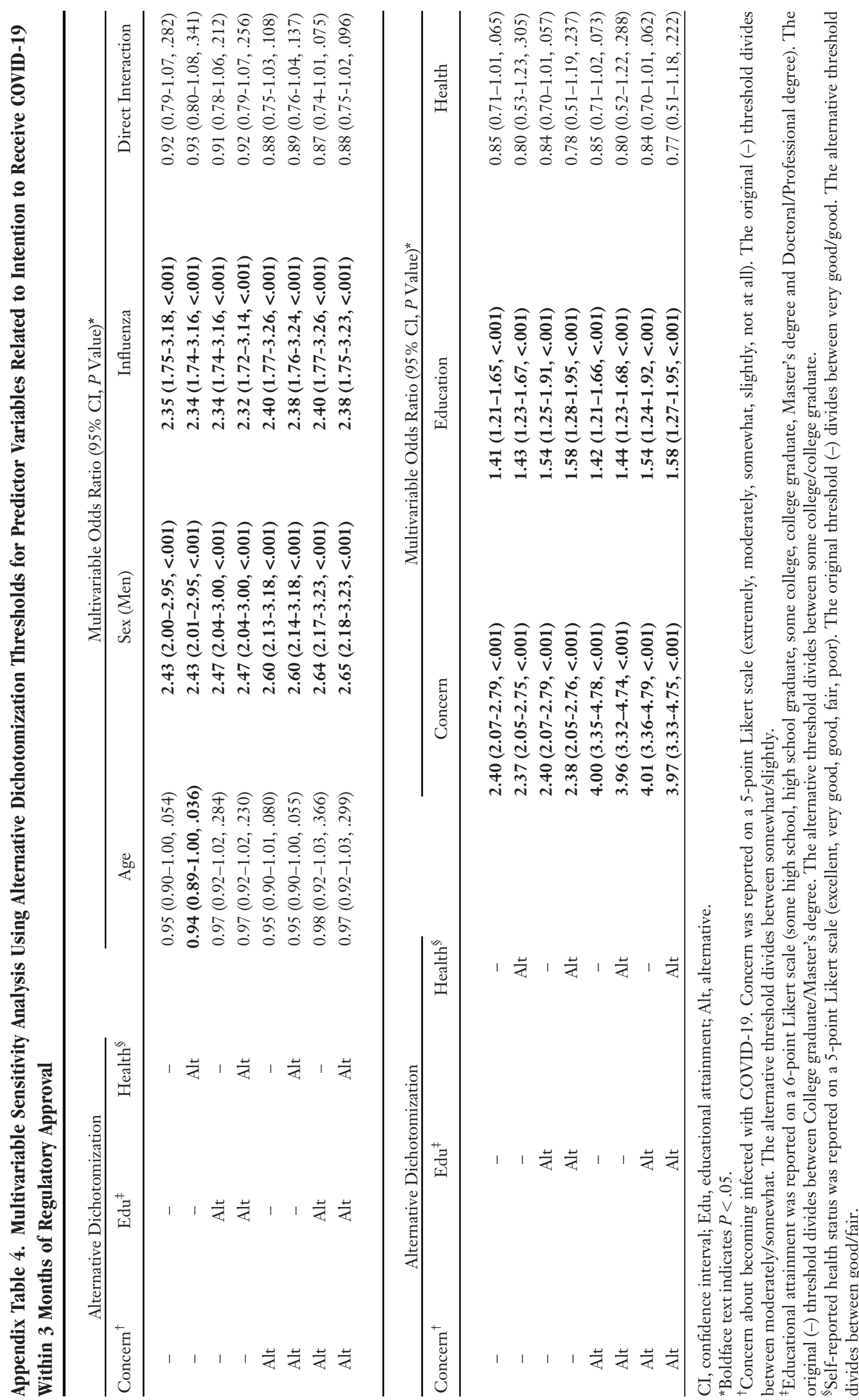


Appendix Table 5. Bivariable Sensitivity Analysis Using Alternative Dichotomization Thresholds for Response Variable: Intention to Receive COVID-19 Within 1 Month (Rather Than 3 Months) of Regulatory Approval

\begin{tabular}{|c|c|c|c|}
\hline Variable & cOR (95\% CI) & $P$ Value & Significance* \\
\hline Age, decades & $1.05(0.99-1.10)$ & .079 & \\
\hline $\operatorname{Men}^{\dagger}$ & $2.23(1.89-2.64)$ & $<.001$ & $* * *$ \\
\hline Influenza vaccine ${ }^{\ddagger}$ & $2.44(1.76-3.46)$ & $<.001$ & $* * *$ \\
\hline Viral concern ${ }^{\S}$ & $1.95(1.69-2.25)$ & $<.001$ & $* * *$ \\
\hline Patient interaction" & $1.17(1.01-1.34)$ & .034 & * \\
\hline Higher education ${ }^{\pi}$ & $1.54(1.33-1.77)$ & $<.001$ & $* * *$ \\
\hline Poor health** & $0.85(0.71-1.01)$ & .063 & \\
\hline Alternative viral concern ${ }^{\dagger \dagger}$ & $2.63(2.18-3.18)$ & $<.001$ & $* * *$ \\
\hline Alternative higher education ${ }^{\neq \ddagger}$ & $1.82(1.46-2.28)$ & $<.001$ & $* * *$ \\
\hline Alternative poor health ${ }^{\S \S}$ & $0.78(0.50-1.19)$ & .259 & \\
\hline
\end{tabular}

cOR, crude odds ratio; $\mathrm{CI}$, confidence interval.

*Significance $\left({ }^{*} P<.05,{ }^{* *} P<.01,{ }^{* * *} P<.001\right)$.

${ }^{\dagger}$ Self-reported gender.

${ }^{\ddagger}$ Completion of influenza vaccination in the 2019-2020 season.

\$"Extremely concerned" or "moderately concerned" about becoming infected with COVID-19 on a 5 -point Likert scale.

"Job responsibility involving direct patient interaction.

ॠMaster's degree or Doctorate.

** Reporting anything other than "Excellent" or "Very Good" health on a 5-point Likert scale.

t†"Extremely concerned", "moderately concerned", or "somewhat concerned" about becoming infected with COVID-19 on a 5 point Likert scale.

${ }^{\sharp \neq}$ College graduate, Master's degree, or Doctorate/Professional degree.

${ }^{\$ \S}$ Reporting anything other than "Excellent", "Very Good", or "Good" health on a 5-point Likert scale. 
Appendix Table 6. Multivariable Sensitivity Analysis Using Alternative Dichotomization Thresholds for Response Variable: Intention to Receive COVID-19 Within 1 Month (Rather Than 3 Months) of Regulatory Approval

\begin{tabular}{|c|c|c|c|c|c|c|c|}
\hline \multicolumn{3}{|c|}{ Alternative Dichotomization } & \multicolumn{5}{|c|}{ Multivariable Odds Ratio $(95 \% \mathrm{Cl}, P \text { Value })^{*}$} \\
\hline Concern $^{\dagger}$ & $\mathrm{Edu}^{\ddagger}$ & Health $^{\S}$ & \multicolumn{2}{|c|}{ Age } & Sex (Men) & Influenza & Direct Interaction \\
\hline- & - & - & \multicolumn{2}{|c|}{$1.00(0.95-1.06, .918)$} & $2.25(1.89-2.68,<.001)$ & $2.21(1.57-3.18,<.001)$ & $1.16(0.99-1.35, .064)$ \\
\hline- & - & Alt & \multicolumn{2}{|c|}{$1.00(0.94-1.05, .938)$} & $2.25(1.89-2.68,<.001)$ & $2.20(1.57-3.16,<.001)$ & $1.17(1.00-1.36, .047)$ \\
\hline- & Alt & - & \multicolumn{2}{|c|}{$1.02(0.97-1.08, .427)$} & $2.28(1.91-2.71,<.001)$ & $2.21(1.57-3.17,<.001)$ & $1.14(0.98-1.33, .090)$ \\
\hline- & Alt & Alt & \multicolumn{2}{|c|}{$1.02(0.97-1.07, .508)$} & $2.28(1.92-2.71,<.001)$ & $2.19(1.56-3.15,<.001)$ & $1.15(0.99-1.34, .070)$ \\
\hline Alt & - & - & \multicolumn{2}{|c|}{$1.01(0.96-1.07, .706)$} & $2.28(1.92-2.72,<.001)$ & $2.23(1.58-3.21,<.001)$ & $1.12(0.96-1.30, .160)$ \\
\hline Alt & - & Alt & \multicolumn{2}{|c|}{$1.01(0.95-1.06, .830)$} & $2.29(1.92-2.73,<.001)$ & $2.22(1.57-3.19,<.001)$ & $1.13(0.97-1.31, .128)$ \\
\hline Alt & Alt & - & \multicolumn{2}{|c|}{$1.03(0.98-1.09, .269)$} & $2.31(1.94-2.75,<.001)$ & $2.23(1.58-3.21,<.001)$ & $1.10(0.95-1.29, .209)$ \\
\hline Alt & Alt & Alt & \multicolumn{2}{|c|}{$1.03(0.97-1.08, .324)$} & $2.32(1.94-2.76,<.001)$ & $2.22(1.57-3.19,<.001)$ & $1.11(0.95-1.30, .174)$ \\
\hline \multicolumn{4}{|c|}{ Alternative Dichotomization } & \multicolumn{4}{|c|}{ Multivariable Odds Ratio (95\% Cl, $P$ Value) ${ }^{*}$} \\
\hline Concern $^{\dagger}$ & & $\mathrm{du}^{\ddagger}$ & Health ${ }^{\S}$ & & Concern & Education & Health \\
\hline - & & - & - & $2.02(1$ & $.74-2.35,<.001)$ & $1.29(1.11-1.51, .001)$ & $0.84(0.70-1.01, .066)$ \\
\hline- & & - & Alt & $2.00(1$ & $.72-2.32,<.001)$ & $1.31(1.13-1.53,<.001)$ & $0.82(0.52-1.27, .386)$ \\
\hline- & & Alt & - & $2.03(1$ & $.74-2.36,<.001)$ & $1.49(1.19-1.89,<.001)$ & $0.84(0.70-1.01, .065)$ \\
\hline - & & Alt & Alt & $2.00(1$ & $.73-2.33,<.001)$ & $1.53(1.22-1.93,<.001)$ & $0.80(0.51-1.24, .333)$ \\
\hline Alt & & - & - & $2.74(2$ & $.26-3.34,<.001)$ & $1.30(1.12-1.52,<.001)$ & $0.86(0.72-1.03, .101)$ \\
\hline Alt & & - & Alt & $2.72(2$ & $.24-3.31,<.001)$ & $1.32(1.13-1.54,<.001)$ & $0.84(0.53-1.29, .429)$ \\
\hline Alt & & Alt & - & $2.75(2$ & $.27-3.35,<.001)$ & $1.51(1.20-1.91,<.001)$ & $0.86(0.72-1.03, .100)$ \\
\hline Alt & & Alt & Alt & $2.73(2$ & $.25-3.32,<.001)$ & $1.54(1.22-1.94,<.001)$ & $0.82(0.52-1.26, .370)$ \\
\hline
\end{tabular}

CI, confidence interval; Edu, educational attainment; Alt, alternative.

*Boldface text indicates $P<.05$.

${ }^{\dagger}$ Concern about becoming infected with COVID-19. Concern was reported on a 5-point Likert scale (extremely, moderately, somewhat, slightly, not at all). The original (-) threshold divides between moderately/somewhat. The alternative threshold divides between somewhat/slightly.

${ }^{\ddagger}$ Educational attainment was reported on a 6-point Likert scale (some high school, high school graduate, some college, college graduate, Master's degree and Doctoral/Professional degree). The original (-) threshold divides between College graduate/Master's degree. The alternative threshold divides between some college/college graduate.

${ }^{\S}$ Self-reported health status was reported on a 5-point Likert scale (excellent, very good, good, fair, poor). The original threshold (-) divides between very good/good. The alternative threshold divides between good/fair.

Appendix Table 7. Bivariable Sensitivity Analysis Using Discretized Age

\begin{tabular}{|c|c|c|c|c|}
\hline Response (Intention)* & Predictor (Age) & cOR $(95 \% \mathrm{CI})$ & $P$ Value & Significance $^{\dagger}$ \\
\hline 3 months & Age 30 to 39 years $^{\ddagger}$ & $0.83(0.69-1.01)$ & .058 & \\
\hline 3 months & Age 40 to 54 years $^{\ddagger}$ & $0.84(0.69-1.01)$ & .062 & \\
\hline 3 months & Age $>54$ years $^{\ddagger}$ & $0.98(0.80-1.21)$ & .877 & \\
\hline Alt: 1 month & Age 30 to 39 years $^{\ddagger}$ & $0.93(0.77-1.13)$ & .483 & \\
\hline Alt: 1 month & Age 40 to 54 years $^{\ddagger}$ & $0.94(0.78-1.14)$ & .532 & \\
\hline Alt: 1 month & Age $>54$ years $^{\ddagger}$ & $1.12(0.91-1.37)$ & .289 & \\
\hline
\end{tabular}

cOR, crude odds ratio; CI, confidence interval; Alt, alternative.

*Intention to receive COVID-19 within 3 months or 1 month (Alt) of regulatory approval.

${ }^{\dagger}$ Significance $\left({ }^{*} P<.05,{ }^{* *} P<.01\right.$, $\left.{ }^{* * *} P<.001\right)$.

${ }^{\ddagger}$ Odds ratio relative to the reference class, age $<30$ years. 


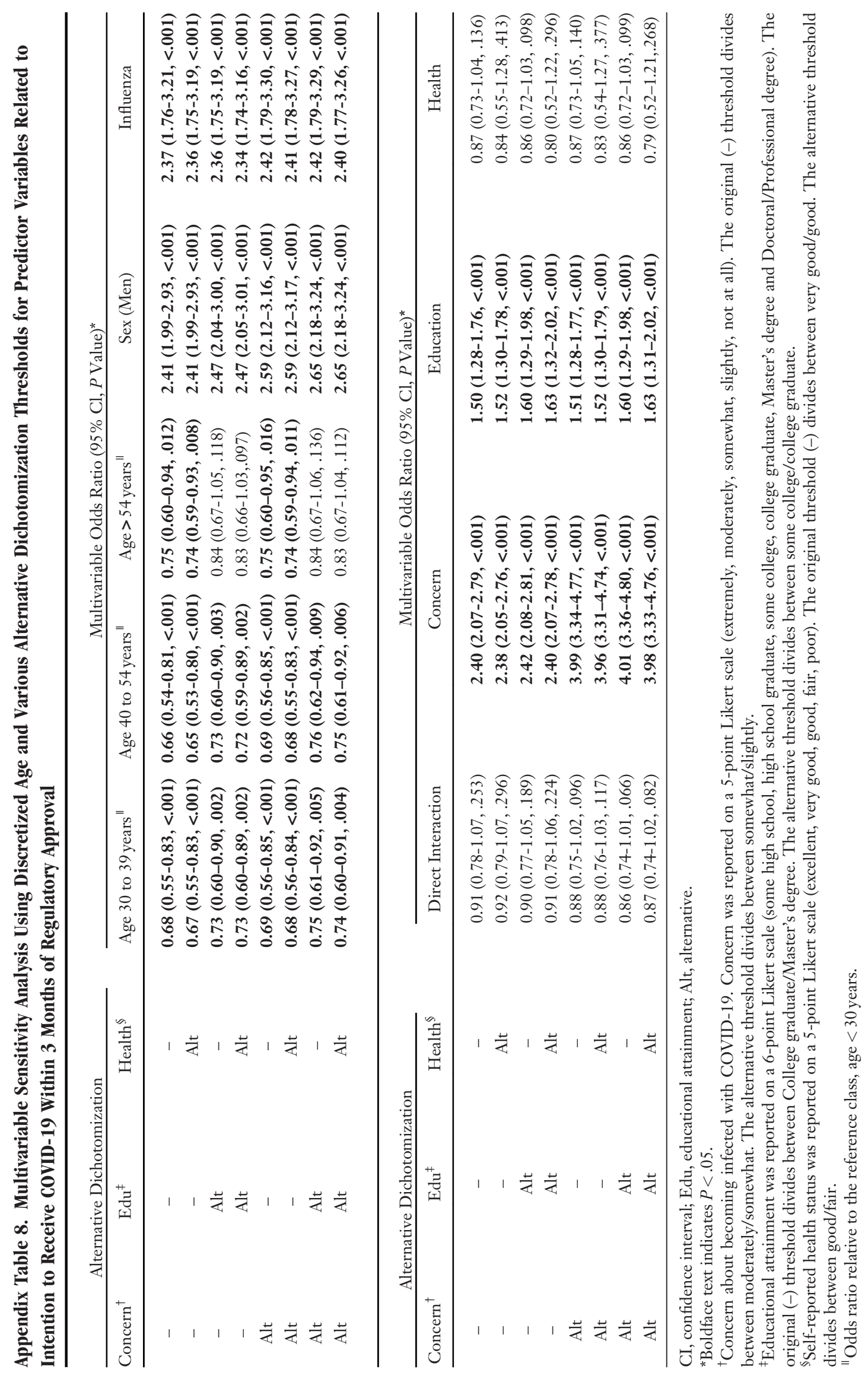

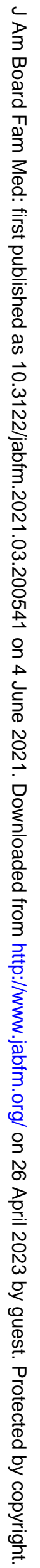




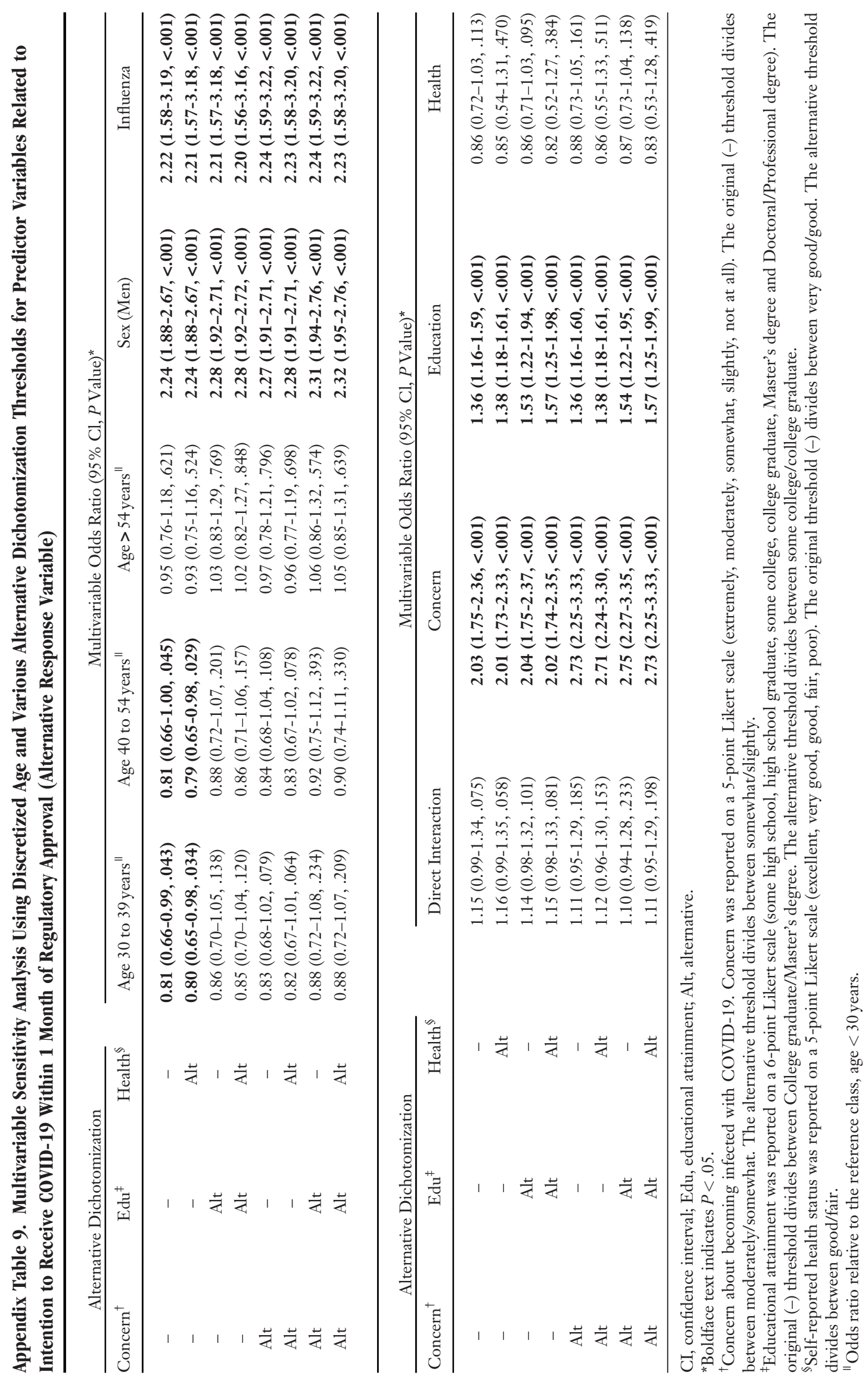

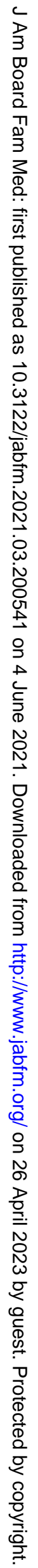




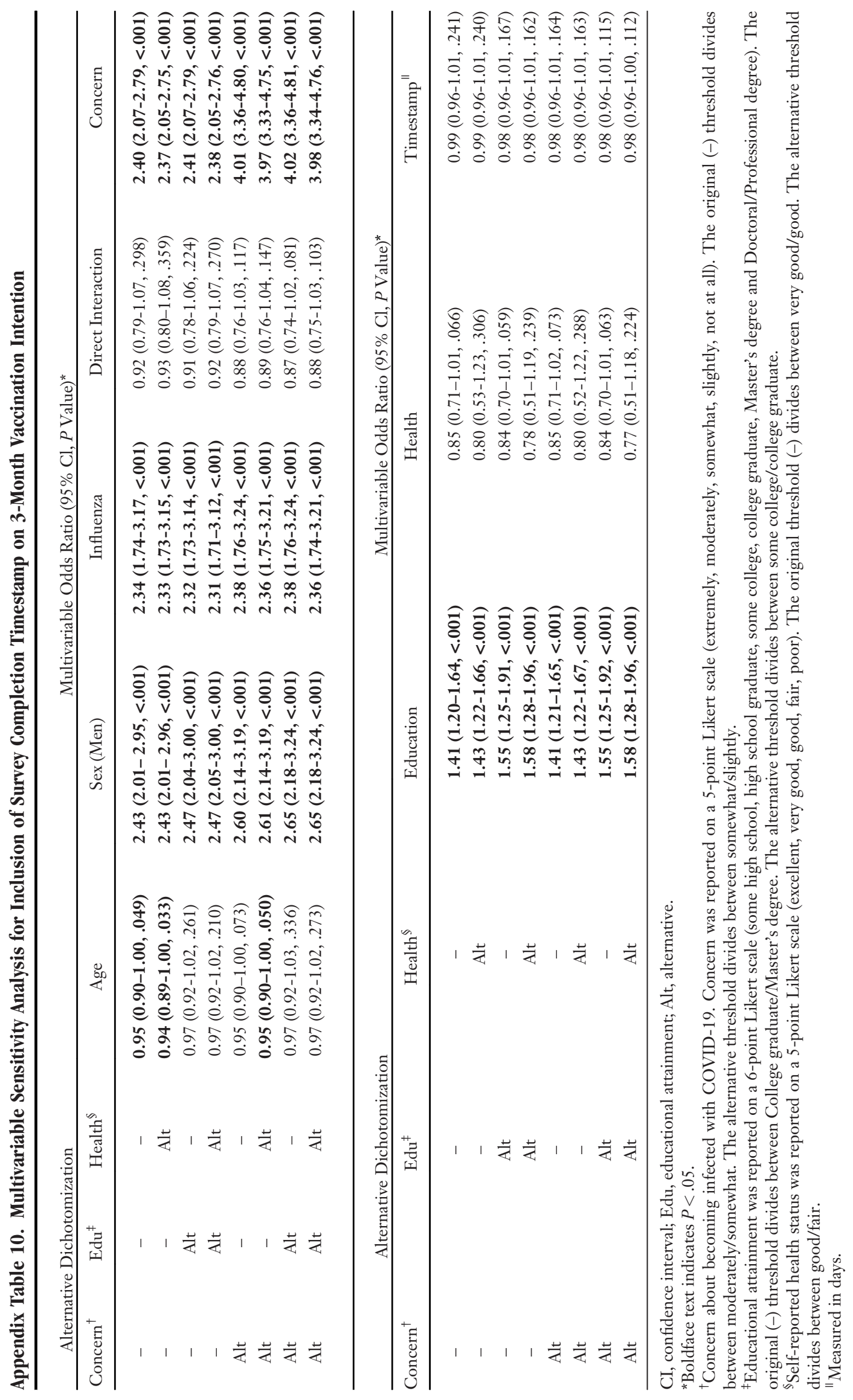

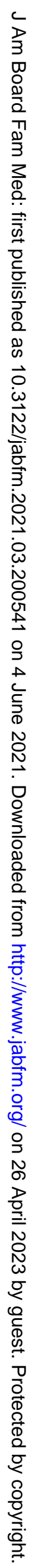




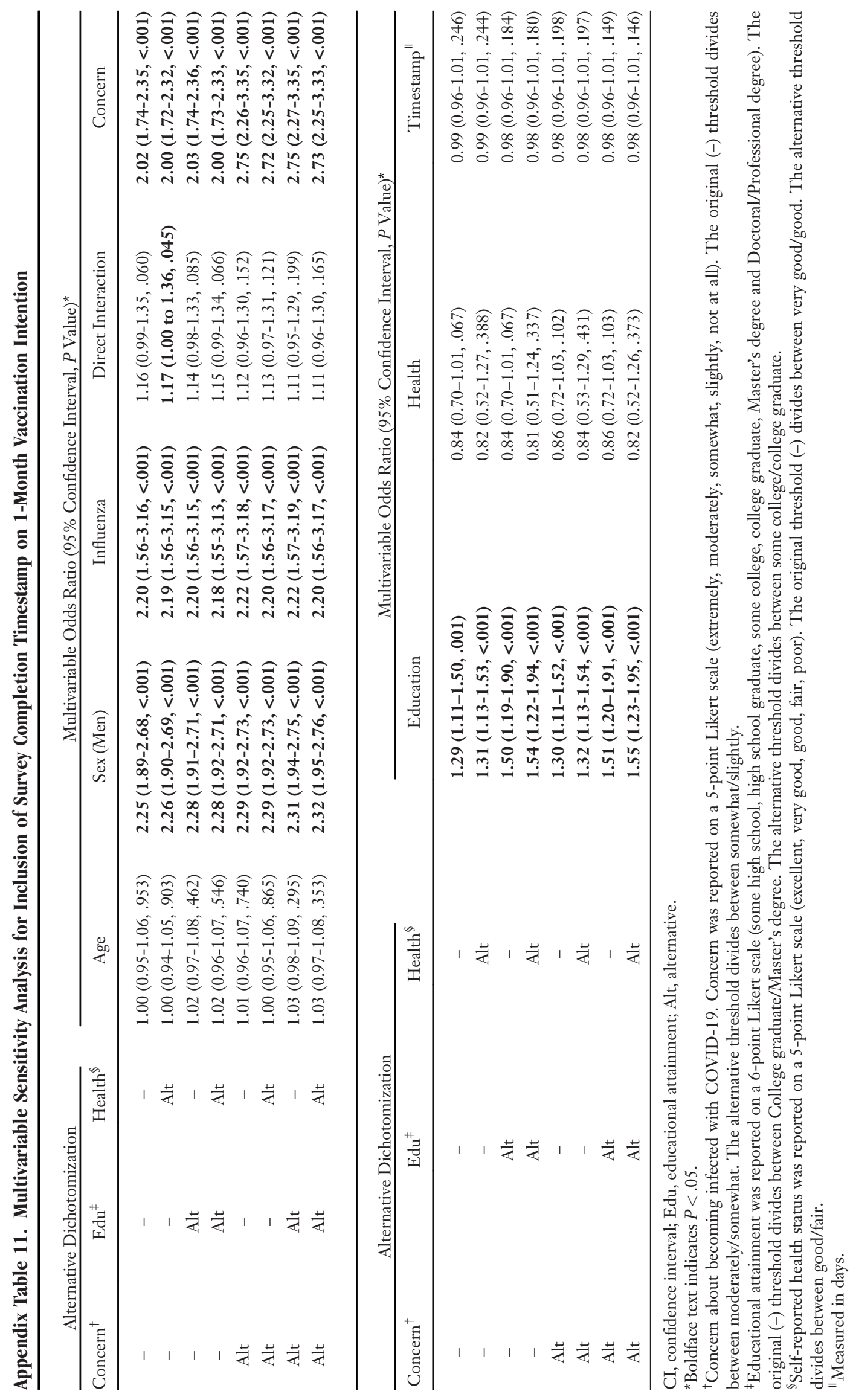

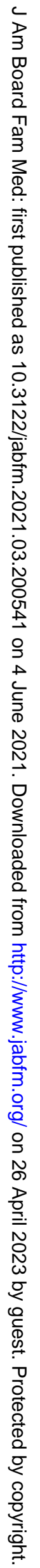


Appendix Table 12. Bivariable Sensitivity Analysis Including Race

\begin{tabular}{|c|c|c|c|c|}
\hline Response (Intention)* & Predictor (Race) & cOR (95\% CI) & $P$ Value & Significance $^{\dagger}$ \\
\hline 3 months & Black or African American ${ }^{\ddagger}$ & $0.16(0.10-0.25)$ & $<.001$ & $* * *$ \\
\hline 3 months & $\operatorname{Asian}^{\ddagger}$ & $1.53(1.04-2.29)$ & .036 & * \\
\hline 3 months & Other/Multiple race $^{\ddagger}$ & $0.65(0.48-0.88)$ & .006 & $* *$ \\
\hline Alt: 1 month & Black or African American ${ }^{\ddagger}$ & $0.21(0.11-0.37)$ & $<.001$ & $* * *$ \\
\hline Alt: 1 month & $\operatorname{Asian}^{\ddagger}$ & $1.08(0.75-1.56)$ & .677 & \\
\hline Alt: 1 month & Other/Multiple race ${ }^{\ddagger}$ & $0.87(0.63-1.20)$ & .401 & \\
\hline
\end{tabular}

cOR, crude odds ratio; CI, confidence interval; Alt, alternative.

*Intention to receive COVID-19 within 3 months or 1 month (Alt) of regulatory approval.

${ }^{\dagger}$ Significance $\left({ }^{*} P<.05,{ }^{* *} P<.01\right.$, $\left.{ }^{* * *} P<.001\right)$.

${ }^{\ddagger}$ Odds ratio relative to the reference class, White race. 


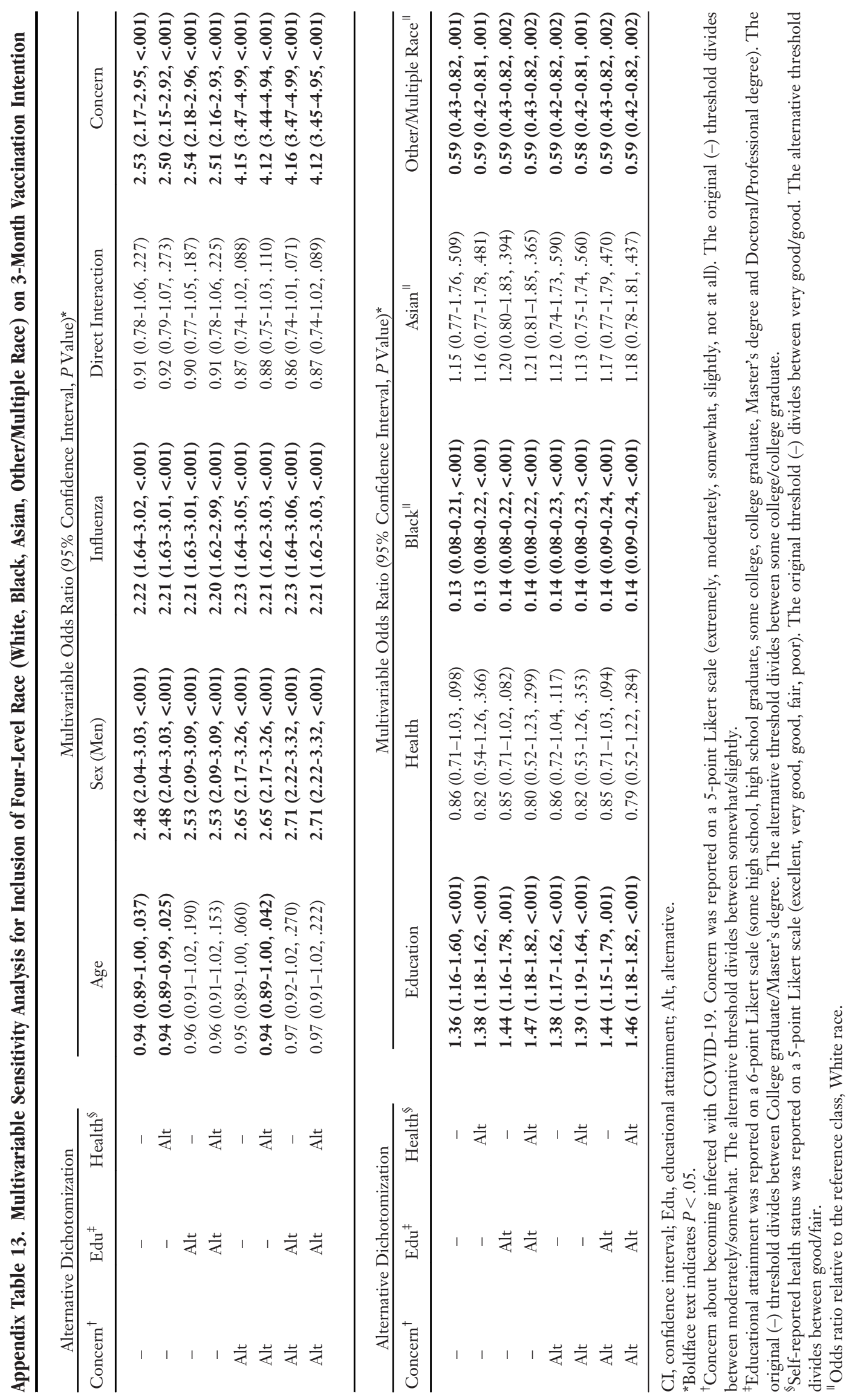

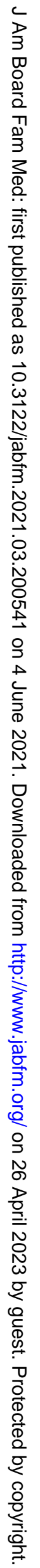




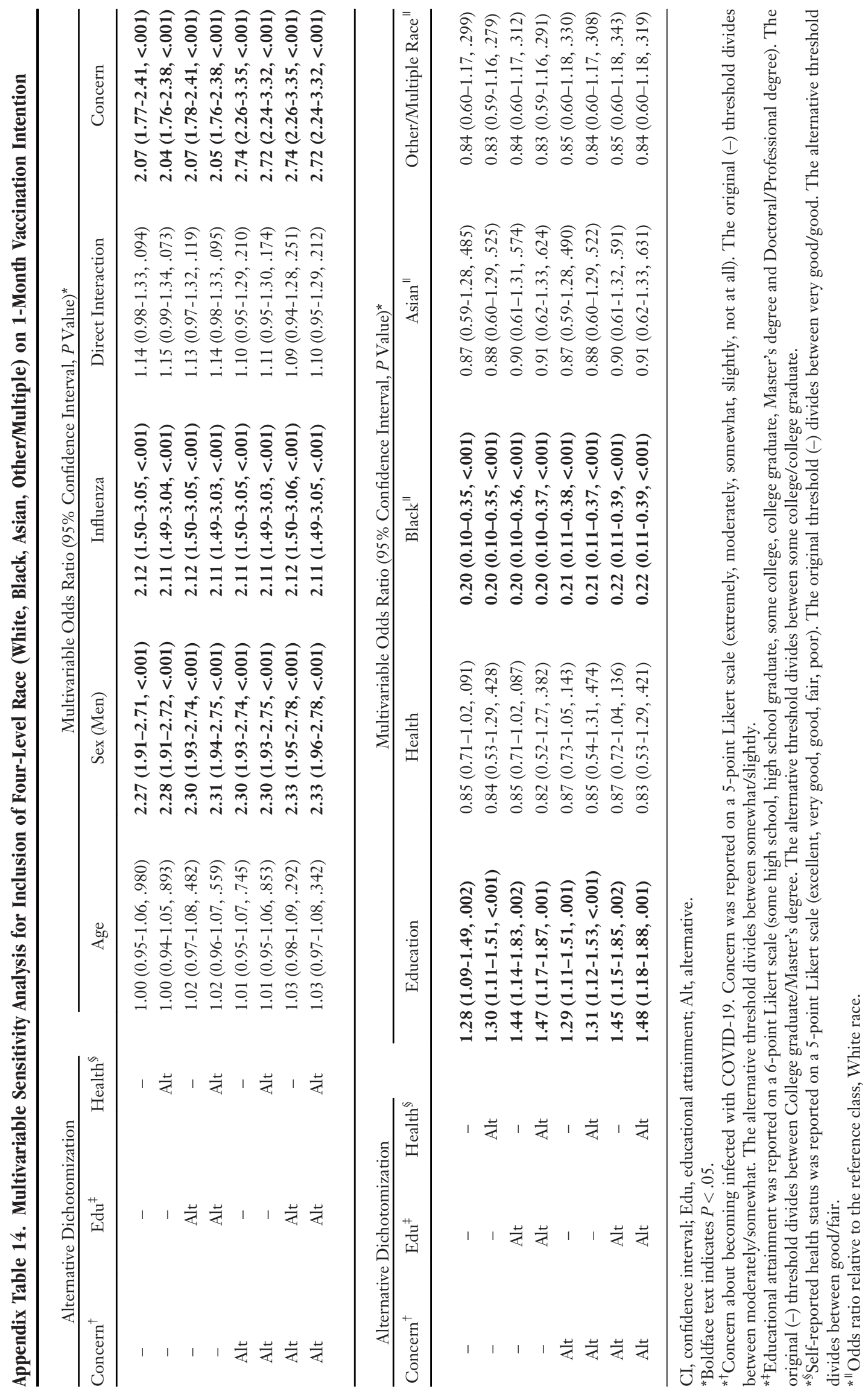

